\title{
Endometriosis in broad ligament: a rare case
}

\section{Rooplekha Chauhan, Ruchita Dadhich, Bharti Sahu, Sonal Sahni*}

Department of Obstetrics and Gynecology, NSCB Medical College, Jabalpur, Madhya Pradesh, India

Received: 11 April 2017

Accepted: 08 May 2017

\section{*Correspondence:}

Dr. Sonal Sahni,

E-mail: drruchita.dadhich@gmail.com

Copyright: (c) the author(s), publisher and licensee Medip Academy. This is an open-access article distributed under the terms of the Creative Commons Attribution Non-Commercial License, which permits unrestricted non-commercial use, distribution, and reproduction in any medium, provided the original work is properly cited.

\begin{abstract}
Endometriosis is a relatively common entity among females presenting with abdominal pain and infertility. The endometriosis of broad ligament is a very rare yet interesting condition. In majority of the reported cases, endometriosis of broad ligament had recurrence after surgical excision. We are reporting one such case in a young nulliparous woman from Jabalpur Madhya Pradesh.
\end{abstract}

Keywords: Broad ligament endometriosis

\section{INTRODUCTION}

Anatomic defects of the broad ligament can be either congenital or acquired. The posterior broad ligament can frequently be affected by endometriosis, especially in the presence of endometrioma. ${ }^{1}$ Peritoneal endometriosis presenting as a tumor is very rare condition. Endometriosis of the broad ligament has been reported as early as in $1926 .{ }^{2}$ However since then very few cases has been reported from India. ${ }^{3}$

\section{CASE REPORT}

A 20-year-old nulliparous female, married for 6 months presented in the gynecology outpatient department with complaints of recurrent abdominal pain since, 3 months. She was normotensive, euglycemic, euthyroid with regular menstrual cycle. On clinical examination uterus was normal size, anteverted and tenderness was present in right fornix.

Transvaginal Ultrasonography suggested $4 \times 3.8 \mathrm{~cm}$ size, well defined thick walled cystic lesion with internal echoes and fluid level, with provisional diagnosis of dermoid cyst in right adnexa.
The patient had undergone diagnostic laparoscopy three months back for similar complaints which clearly demonstrated the presence of a mass within the broad ligament and perceived to be a case of broad ligament fibroid. Hence patient was taken considered for exploratory laparotomy for acute abdominal pain.

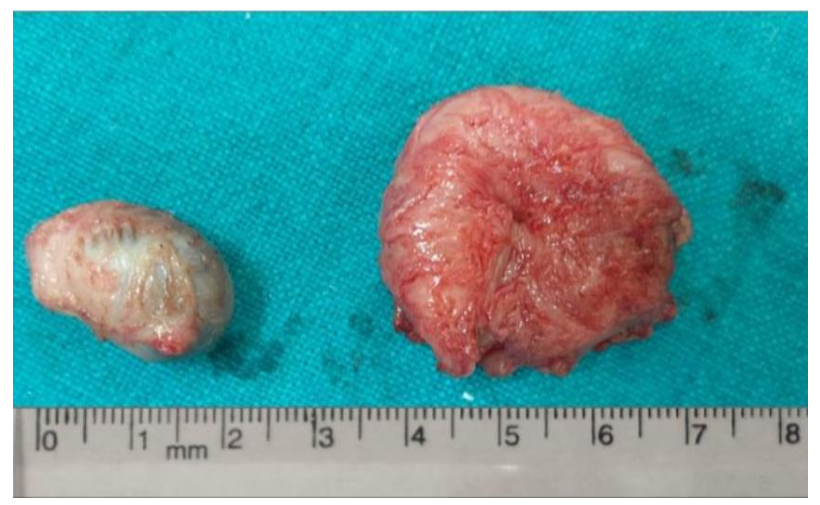

Figure 1: Gross picture of broad ligament endometriotic cysts.

Per operatively, 2 masses of approximately $3 \times 3 \mathrm{~cm}$ and $2 \times 2 \mathrm{~cm}$ were identified in the broad ligament which were 
enucleated and excised smoothly as if fibroid until it ruptures inadvertently and yielded chocolate colored fluid suggestive of endometriosis. ${ }^{4}$

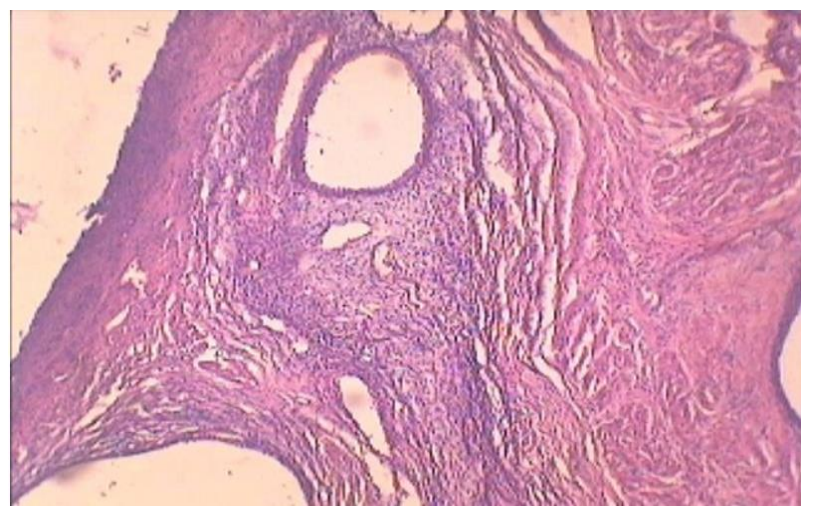

Figure 2: Hematoxylin and eosin stained section of endometriotic cyst (10 X magnification).

The cyst had no connection to fallopian tube, round ligament or uterus. No features of angiogenesis in and around the cysts could be identified. The uterus, cervix, fallopian tubes, ovaries and uterosacral ligaments were unremarkable. There were no endometriotic deposits at any other site. Histopathological examination showed fibrocollagenous tissue of the cyst wall, in which foci of haemorrhage were seen. There was ectopic endometrial tissue surrounded by inflammatory cells confirmatory of endometriotic cyst. No ovarian tissue was identified.

\section{DISCUSSION}

Endometriosis is defined as the presence or growth of ectopic endometrial tissue. Sporadic case reports of endometriosis in the peritoneum have been published. ${ }^{2-5}$ Endometriosis occurs in $5 \%$ to $10 \%$ of all women of reproductive age worldwide, often resulting in debilitating pain and infertility. Early menarche, frequent menstruations, pelvic pain, infertility and nulliparity are also associated with endometriosis. Commonest site of endometriosis is ovary, which is, followed by pouch of douglas, uterosacral ligaments and rectovaginal septum ${ }^{3}$. Rare sites are: Abdominal scars, bladder/ureter, cervix/vagina, umbilicus, gut, lungs. In peritoneal endometriosis, nodules of less than a few millimeters in diameter are frequently noted, but tumor formation is very rare. ${ }^{5}$ It is Common in the nullipara and the theories in support of implantation are the Sampsons theory of retrograde menstruation, Meyer and Ivanoffs coelomic metaplasia theory, direct implantation theory and Halbans lymphatic theory. ${ }^{3}$ But the location of this endometrioma deep within the broad ligament provides evidence supporting the suggestion that the aetiology of endometriomas can (at least in some cases) be explained by methods other than retrograde menstruation (may be from Müllerian remnants or Meyer and Ivanoffs coelomic metaplasia). ${ }^{6}$ The most common manifestation is the
Pelvic pain with dysmenorrhea or dyspareunia or dyschezia. Some patients may have menorrhagia, polymenorrhea, infertility. Cyclical changes in the intensity of pain and size of the endometrial implants during menstruation are usually characteristic of classical endometriosis. The broad ligaments are also known as Uterovesical folds of peritoneum or the Rectovaginal folds of peritoneum. The Broad ligaments contains the uterine tube, round ligament of the uterus, ligament of the ovary, uterine vessels, ovarian vessels, uterovaginal and ovarian nerve plexuses, epoophoron, paroophoron, some lymph nodes and lymph vessels and the dense connective tissue of the parametrium. ${ }^{3}$

\section{CONCLUSION}

Although broad ligament endometrioma is a very rare condition but a look out for Endometriosis should be always taken in case of a female presenting with abdominopelvic pain and appropriate and aggressive therapy be initiated as it is a source of great displeasure to females.

\section{Funding: No funding sources Conflict of interest: None declared Ethical approval: Not required}

\section{REFERENCES}

1. Mereu L, Florio P, Carri G, Pontis A, Petraglia F and Mencaglia L. Clinical Outcomes associated with surgical treatment of endometrioma coupled with resection of the posterior broad ligament. International journal of Gynaecol Obstetr. 2012;116(1):57-60.

2. Whitehouse HB. Endometrioma between the Layers of the Broad Ligament. Proceedings of the Royal Society of Medicine. 1926;19:16.

3. ul Hassan A, Khanday S, Rasool Z, Ara R, Salem A, Rasool Z. The rare case of broad ligament endometriosis. International Journal of Medical Science Research and Practice. 2015;2(1):47-8.

4. Novak E. Berek, Berek JS. Novak's gynecology. Lippincott Williams and Wilkins; 2012.

5. Itoga T, Matsumoto T, Suzuki C, Miyazaki R, Kurosaki Y, Suda K. Peritoneal endometriosis in the broad ligament presenting as a large tumor. Pathology international. 2002;52(5-6):410-5.

6. Trehan A, Trehan AK. Endometrioma contained within the broad ligament. BMJ case reports. 2014;2014:bcr2013203441.

7. Rizzuto MI, Odejinmi F. Laparoscopic 'day case' management of an 'endometrioma' within the broad ligament. J Obstetr Gynaecol. 2009;29(6):561-2.

Cite this article as: Chauhan R, Dadhich R, Sahu B, Sahni S. Endometriosis in broad ligament: a rare case. Int J Reprod Contracept Obstet Gynecol 2017;6:2676-7. 